\title{
Erratum to: Evaluation of the short-term efficacy of NSAIDs on patients with active ankylosing spondylitis in daily practice: a 3-month, longitudinal, observational study
}

\author{
Muhammet Cinar - Ayhan Dinc - Ismail Simsek - Hakan Erdem • \\ Bayram Koc $\cdot$ Salih Pay $\cdot$ Selim Kilic
}

Published online: 19 March 2010

(C) Springer-Verlag 2010

\section{Erratum to: Rheumatol Int (2010) 30:331-340 \\ DOI 10.1007/s00296-009-0963-y}

This article was unfortunately submitted with few errors in the issue 30(3) which we would like to correct here.

First; a sentence in the last paragraph of the results section on page 336: "Indometacin was given to $30.3 \%$ of patients, acemetacine was given to $28.6 \%$ of the patients, and other NSAIDs (diclofenac sodium, flurbiprophene, and celecoxib) were given to $26.7 \%$ of patients who responded to the treatment" causes misunderstanding.

The online version of the original article can be found under doi:10.1007/s00296-009-0963-y.

M. Cinar · B. Koc

Division of Internal Medicine,

Gulhane Military School of Medicine, Ankara, Turkey

A. Dinc · I. Simsek · H. Erdem · S. Pay

Division of Rheumatology,

Gulhane Military School of Medicine, Ankara, Turkey

S. Kilic

Department of Epidemiology and Public Health,

Gulhane Military School of Medicine, Ankara, Turkey

A. Dinc ( $\square)$

GATA Romatoloji BD, Etlik, 06018 Ankara, Turkey

e-mail: adinc@gata.edu.tr; adinc@tr.net
The correct sentence is: " $30.3,28.6$, and $26.7 \%$ of patients who treated with indometacin, acemetacin, and other NSAIDs (diclofenac sodium, flurbiprophene, celecoxib), in that order, had responded to their treatments."

Second; the word "acemethazine" is incorrectly written at several lines in the text, however, the correct word should be as "acemetacin". 